\title{
Formation of the Glassy State and Mesophase in the Water-Sodium Alginate System
}

\author{
Kunio Nakamura, Tatsuko Hatakeyama, ${ }^{*}$ and Hyoe Hatakeyama** \\ Otsuma Women's University, Chiyoda-ku, Tokyo 102, Japan \\ * Research Institute for Polymers and Textiles, Tsukuba Ibaraki 305, Japan \\ ** Industrial Products Research Institute, Tsukuba, Ibaraki 305, Japan
}

(Received July 17, 1990)

\begin{abstract}
The phase transition of water-sodium alginate with water content $\left(W_{\mathrm{c}}\right)$ (grams of water/gram of dry sample) from 0 to 2.5 was studied using differential scanning calorimetry (DSC). Upon heating, glass transition $\left(T_{\mathrm{g}}\right)$, cold crystallization and melting were observed in the $W_{\mathrm{c}}$ range from 0.49 to 2.5 . At a $W_{\mathrm{c}}$ less than 0.49 , only $T_{\mathrm{g}}$ was observed. During cooling, the crystallization of water in the system was observed from the $W_{\mathrm{c}}=0.77$. The above difference suggests the presence of glassy water which crystallizes during the heating process. The contribution of non-freezing water and glassy water to $T_{\mathrm{g}}$ and $C_{\mathrm{p}}$ of the system was estimated.

KEY WORDS Sodium Alginate / Water / Glass Transition / Meso-Phase / Differential Scanning Calorimetry / Non-Freezing Water / Glassy Water /
\end{abstract}

Alginic acid is a copolysaccharide consisting of D-mannuronic acid and L-guluronic acid extracted from brown masse algae. ${ }^{1-3}$ It has been reported that the polyguluronate sequence in alginic acid forms a special molecular arrangement in water in the presence of calcium ion, which is called the "egg-box model.",4,5 This model shows that water molecules are wrapped with polyguluronate molecular sequence and arranged in a regular structure. Sodium alginate is a polyelectrolyte widely used in various fields, for example, as a stabilizer in the food industry and a dying adhesive in the textile industry.

The molecular motion of the waterpolyelectrolytes and gels has been investigated by several research groups. ${ }^{6-10}$ It has also been reported that polyelectrolytes take an ordered molecular arrangement in dilute ${ }^{11,12}$ and in concentrated aqueous solutions. ${ }^{13,14}$

In our previous studies using thermal analysis and nuclear magnetic relaxation (NMR), ${ }^{6,7,14-16}$ we reported that many polyelectrolytes, such as sodium salts of carboxymethylcellulose, ${ }^{6}$ cellulose sulfate $^{7}$ xanthan gum, ${ }^{17}$ lignosulfonic $\operatorname{acid}^{18}$ and polystyrene sulfonate ${ }^{15}$ form a mesophase, in the water contents $\left(W_{\mathrm{c}}\right.$ 's, grams of water per gram of polyelectrolyte) ranging from $c a .0 .5$ to $c a .2 .5$.

In the present paper, the thermal behaviour of the glassy state and the liquid crystalline state of the water-sodium alginate system is investigated by differential scanning calorimetry (DSC).

\section{EXPERIMENTAL}

\section{Sample Preparation}

Sodium alginate (NaALG) was commercially obtained from Wako Chemicals Co. with a 1.1 degree of substitution.

\section{Differential Scanning Calorimetry (DSC)}

A Du Pont 910 DSC equipped with cooling apparatus was used and a DSC sample was prepared in the following way. NaALG and water were weighed and mixed in a sample tube 
which was allowed to stand for one night. A certain amount of NaALG-water sample was weighed in a DSC aluminium volatile sample pan.

Water content $\left(W_{\mathrm{c}}\right)$ was calculated from the following equation: $W_{\mathrm{c}}(\mathrm{g} / \mathrm{g})=$ (weight of added water $(\mathrm{g}) /$ weight of dry NaALG $(\mathrm{g})$ )

DSC curves were obtained in the temperature range from $-150^{\circ} \mathrm{C}$ to $70^{\circ} \mathrm{C}$. The scanning rate was $10^{\circ} \mathrm{C} \min ^{-1}$. Phase transition temperature and enthalpy of transition of sorbed water were calibrated using pure water as a standard. After a DSC measurement, the sample pan was weighed again to confirm that no weight loss had taken place during the scan. Transition temperatures and heat of transition were calculated according to the method previously reported. ${ }^{14,15}$ The bound water content was calculated by the method reported previously. ${ }^{16-19}$

\section{RESULTS AND DISCUSSION}

Figure 1 shows DSC heating curves of the water-NaALG system. The samples were heated at $10^{\circ} \mathrm{C} \mathrm{min}^{-1}$ after cooling from $20^{\circ} \mathrm{C}$ to $-150^{\circ} \mathrm{C}$ at the cooling rate of $10^{\circ} \mathrm{C} \mathrm{min}^{-1}$. The sample with $W_{\mathrm{c}}=0.31$ did not show any phase transition, except the shift of base line at $-40^{\circ} \mathrm{C}$ due to glass transition. Similar results were obtained for the samples with $W_{\mathrm{c}}$ less than $c a$. 0.45. This indicates that water molecules are strongly restricted by $\mathrm{NaALG}$ molecules and do not form crystals in $W_{\mathrm{c}}$ 's less than 0.45 . This kind of water has been designated as non-freezing water $\left(W_{\text {nf }}\right) .^{19}$ When $W_{\mathrm{c}}$ exceeded 0.45 , an endothermic peak at around $0^{\circ} \mathrm{C}$ appeared in each of DSC curves suggesting the presence of freezing water in the system. For example, in the DSC curve of the sample with $W_{\mathrm{c}}=0.77$, glass transition temperature $\left(T_{\mathrm{g}}\right)$ was observed at $-80^{\circ} \mathrm{C}$, an exotherm due to cold-crystallization $\left(T_{\mathrm{cc}}\right)$ at around $-50^{\circ} \mathrm{C}$ and a melting $\left(T_{\mathrm{m}}\right)$ peak at $-5^{\circ} \mathrm{C}$. As shown in Figure 1, transition temperatures, $T_{\mathrm{g}}, T_{\mathrm{cc}}$, and $T_{\mathrm{m}}$ vary as a function of $W_{\mathrm{c}}$.

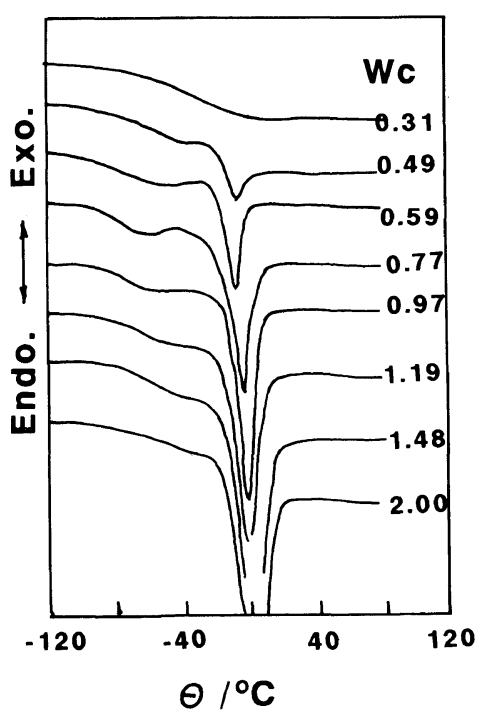

Figure 1. DSC heating curves of water-NaALG system containing various water contents $\left(W_{\mathrm{c}}\right)$. Numericals in figure show $W_{\mathrm{c}}$.

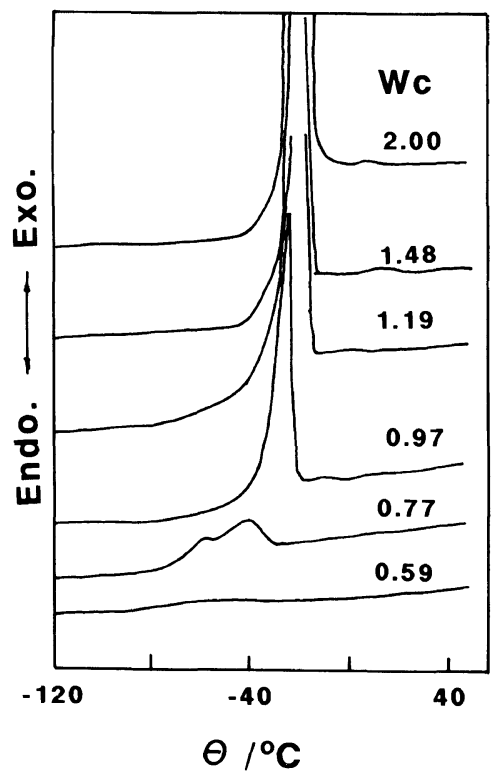

Figure 2. DSC cooling curves of water-NaALG system containing various water contents $\left(W_{\mathrm{c}}\right)$. Numerals in figure show $W_{\mathrm{c}}$.

Figure 2 shows DSC cooling curves of water-NaALG system. When the sample with $W_{\mathrm{c}}=0.59$ was cooled at $10^{\circ} \mathrm{Cmin}^{-1}$ to $-150^{\circ} \mathrm{C}$, no first-order phase transition was 
detected. This indicated that all of the water molecules in the system were non-freezing water. It is notable that the DSC heating curve of the sample with $W_{\mathrm{c}}=0.59$ showed not only $T_{\mathrm{g}}$ but also $T_{\mathrm{cc}}$ and $T_{\mathrm{m}}$. This fact suggested that structural changes of the system took place during the heating process. When $W_{\mathrm{c}}$ exceeded ca. 0.7 , a broad exotherm due to crystallization of water was observed. This peak became sharper and shifted to the high temperature side with increasing $W_{\mathrm{c}}$. The crystallization curves of the samples with high $W_{\mathrm{c}}$ (2.0 and above) were similar to that of pure water.

From the DSC curves shown in Figures 1 and 2 , it is apparent that there are three types of water in the water-NaALG system; the first type of water is non-freezing water in $W_{\mathrm{c}}$ ranging from 0 to 0.45 . This kind of water shows no first-order phase transition in either the heating or cooling processes. The second type is bound water observed in $W_{\mathrm{c}}$ ranging from $c a .0 .45$ to $c a .0 .68$ and this type of water does not crystallize during cooling but crystallizes at a temperature higher than $T_{\mathrm{g}}$ in heating process. The third type of water shows the first-order phase transition in both heating and cooling.

The maximum amount of $W_{\mathrm{nf}}$ observed in DSC heating was 0.45 and that observed in DSC cooling curve was 0.68 , suggesting the presence of glassy water. When the system was cooled at $10^{\circ} \mathrm{C} \mathrm{min}^{-1}$, the system froze in the non-equilibrium state due to super-cooling. On this account, the molecular motion of water molecules in the system which are capable of crystallization in the equilibrium condition, ceased without forming ice. On heating, water molecules rearrange with increasing temperature, frozen molecules having unstable structure take a more ordered structure at cold-crystallization temperature. This type of glassy water could be found, even when the cooling rate was slow. Glassy water molecules showed properties similar to non-freezing water molecules at a temperature below $T_{\mathrm{cc}}$.

Figure 3 shows the relationship between

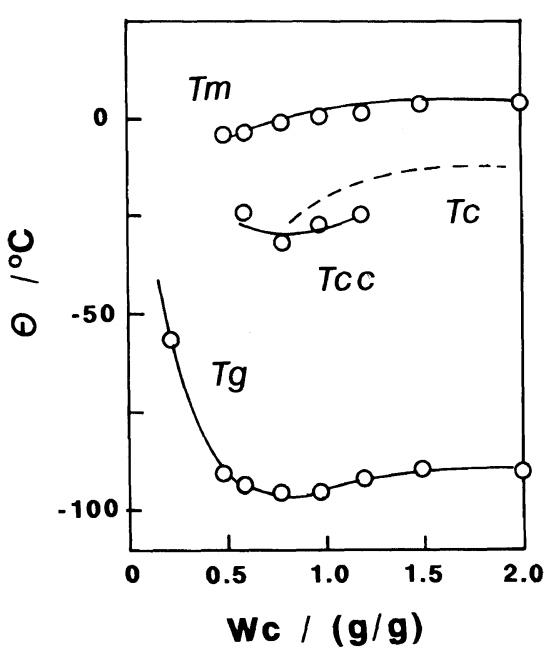

Figure 3. The relationship between phase transition temperatures of water-NaALG system and $W_{\mathrm{c}}$. Dotted line shows the crystallization temperature measured by cooling. $T_{\mathrm{m}}$, melting temperature; $T_{\mathrm{c}}$, crystallization; $T_{\mathrm{cc}}$, cold crystallization; $T_{\mathrm{g}}$, glass transition.

phase transition temperatures and $W_{\mathrm{c}}$. As stated in the experimental section, peak temperature was used as an index of $T_{\mathrm{m}}, T_{\mathrm{cc}}$, and $T_{\mathrm{c}}$. The $T_{\mathrm{m}}$ slightly increased with increasing $W_{\mathrm{c}}$. The $T_{\mathrm{cc}}$ was clearly observed in the $W_{\mathrm{c}}$ less than 1.0. In contrast, it was difficult to distinguish $T_{\mathrm{cc}}$ from the base line at a higher $W_{\mathrm{c}}$. The $T_{\mathrm{g}}$ abruptly decreased in the small $W_{\mathrm{c}}$ region (less than 0.5 ), attained a minimum value at $W_{\mathrm{c}}=0.7$ and then slightly increased with increasing $W_{\mathrm{c}}$. Absolutely dry $\mathrm{NaALG}$ showed no transition from $-150^{\circ} \mathrm{C}$ to $100^{\circ} \mathrm{C}$ by thermal analysis. The variation in $T_{\mathrm{g}}$ shown in Figure 3 suggests a small amount of water in the system induces the molecular motion by breaking ionic and hydrogen bondings between NaALG molecules.

$T_{\mathrm{c}}$ obtained by the DSC cooling curve is shown in Figure 3 as a broken line. The $T_{\mathrm{c}}$ was observed for the system with a higher $W_{\mathrm{c}}$ than 0.77 and shifted to the high temperature, levelling off at $-12^{\circ} \mathrm{C}$.

The results shown in Figure 3 suggest that the molecular motion of the system accelerated with increasing $W_{\mathrm{nf}}$ and then decreased in the 
presence of ice. It is considered that ice presenting in the system disturbed the cooperative molecular motion of NaALG with $W_{\mathrm{nf}}$. This is supported by the fact that the $T_{\mathrm{g}}$ showed constant value in a temperature where $T_{\mathrm{cc}}$ was not observed and $T_{\mathrm{m}}$ was levelled off.

Figure 4 shows the relationships between $W_{\text {nf }}$ 's calculated from DSC heating and cooling curves and $W_{\mathrm{c}}$. The $W_{\mathrm{nf}}$ was calculated from $W_{\mathrm{c}}-W_{\mathrm{f}}=W_{\mathrm{nf}}$, where $W_{\mathrm{f}}$ was obtained from the heat of melting $\left(\Delta H_{\mathrm{m}}\right)$ or the heat of crystallization $\left(\Delta H_{\mathrm{c}}\right)$. The heat of the transition of pure water was used as a standard. The $W_{\text {nf }}$ increases linearly in the $W_{\mathrm{c}}$ range where only $W_{\mathrm{nf}}$ is present in the system. As stated above, freezing water appeared at $W_{\mathrm{c}}=0.45$ in the heating curve and at $W_{\mathrm{c}}=0.68$ in the cooling curve. In both curves $W_{\mathrm{f}}$ reached a maximum at around $W_{\mathrm{c}}=0.8$ and then levelled off at a higher $W_{\mathrm{c}}$ range. The difference between $W_{\mathrm{nf}}$ calculated from $\Delta H_{\mathrm{c}}$ and that from $\Delta H_{\mathrm{m}}$ corresponds to the amount of glassy water.

In Figure 4, mole numbers of non-freezing water attached to each repeating unit of $\mathrm{NaALG}$ which is calculated from $\Delta H$ are also shown. At the maximum, about 8 non-freezing water molecules are attached to each unit and at the saturated region, 6 water molecules are present. When the ionic groups are located in short distance, a part of freezing water behaves as non-freezing water owing to strong molecular interaction. This explains the $\Delta H_{\mathrm{c}}$ and $\Delta H_{\mathrm{m}}$ maxima in Figure 4 . When ice is formed in the system, ice disturbs free molecular motion of NaALG containing non-freezing water and this results $T_{\mathrm{g}}$ increase. Detailed discussion concerning this phenomena was reported previously. ${ }^{17}$ The numbers of nonfreezing water molecules agreed well with those of sodium carboxymethyl-cellulose, ${ }^{6,14}$ cellulose sulfate ${ }^{7}$ and other polyelectrolytes from saccharides. ${ }^{14,17,21}$

Figure 5 shows the heat capacity difference $\left(\Delta C_{\mathrm{p}}\right)$ between the glassy and the liquid states at $T_{\mathrm{g}}$. The $\Delta C_{\mathrm{p}}$ was calculated using the

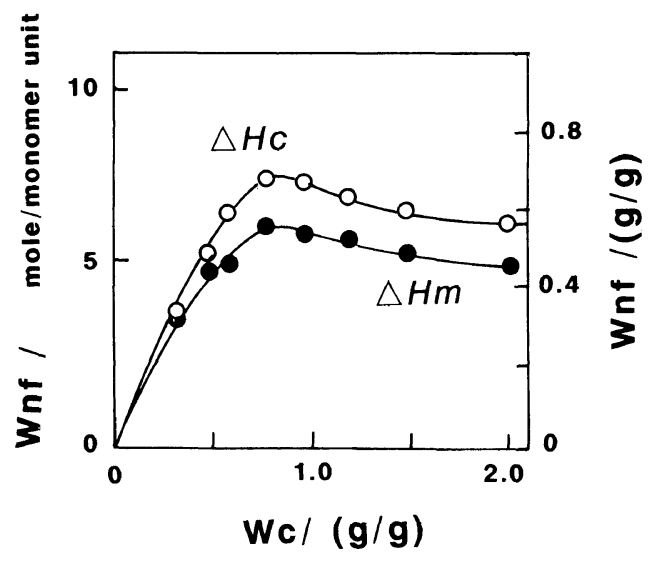

Figure 4. The relationships between $W_{n}$ 's (right axis), number of non-freezing water molecules (left axis) and $W_{\mathrm{c}}$. ○, calculated from $\Delta H_{\mathrm{c}}, \boldsymbol{\odot}$, from $\Delta H_{\mathrm{m}}$.

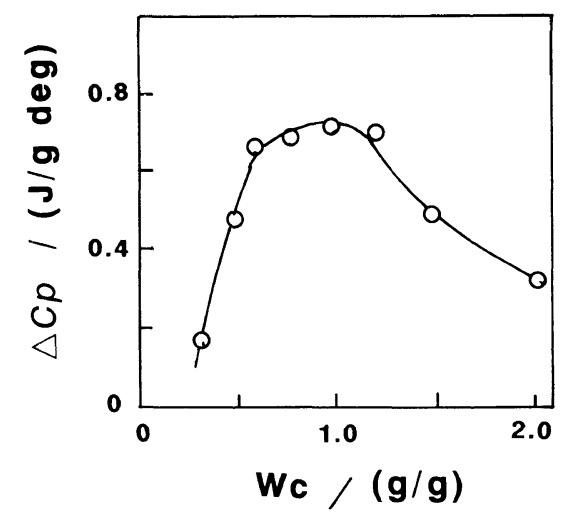

Figure 5. The relationship between the heat capacity difference $\left(\Delta C_{\mathrm{p}}\right)$ between the glassy and liquid states at $T_{\mathrm{g}}$ and $W_{\mathrm{c}}$.

summed weights of dry NaALG and nonfreezing water, since glass transition of the system was concerned by homogeneous nature of both saccharides and water. ${ }^{15}$ The $\Delta C_{\mathrm{p}}$ value increased in $W_{\mathrm{nf}}$ region of the system, reaches a maximum at $W_{\mathrm{c}}=1.0$ and then decreased with increasing amount of free water in the system. The variation of $\Delta C_{\mathrm{p}}$ was almost similar to that of $W_{\mathrm{nf}}$ shown in Figure 4.

It has already been reported that various kinds of polyelectrolytes show liquid crystalline properties when they contain $W_{\mathrm{c}}$ from 0.5 to $2.0 .^{14,22}$ In the DSC curves of water- 


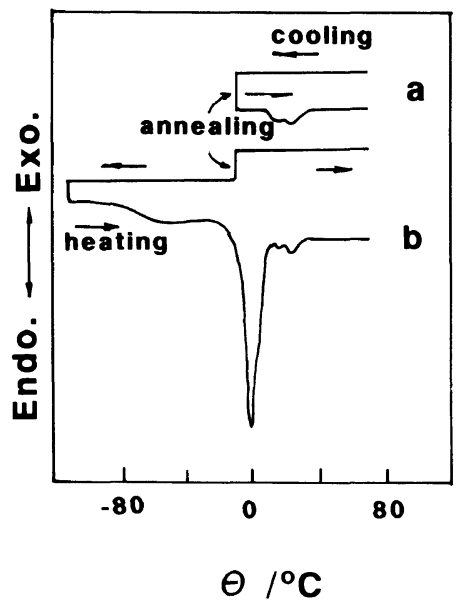

Figure 6. DSC curves of the water-NaALG system with $W_{\mathrm{c}}=0.97$. a, annealing at $-10^{\circ} \mathrm{C} ; \mathrm{b}$, quenched after annealing at $-10^{\circ} \mathrm{C}$.

polyelectrolyte systems, such as water- $\mathrm{Na}$ polystyrene sulfonate, water-Na xanthan, an endothermic peak attributed to the transition from the liquid crystalline state to the isotropic liquid state was observed at a temperature higher than $T_{\mathrm{m}}$ without any annealing. In contrast, the water-NaALG did not show a clear endothermic peak after heating at $10^{\circ} \mathrm{Cmin}^{-1}$. Figure 6 shows the water-NaALG system with $W_{\mathrm{c}}=0.97$ after annealing at $-10^{\circ} \mathrm{C}$, a temperature slightly higher than $T_{\mathrm{c}}$, for one hour. As shown in DSC curve (a) in Figure 6, endothermic peaks are observed at a temperature higher than $T_{\mathrm{m}}$. A similar endothermic peak was also obtained when the sample was quenched after annealing at $-10^{\circ} \mathrm{C}$ as shown in the curve (b) in Figure 6. This indicates that the liquid crystalline phase forms in this system, although it takes time to make an ordered structure.

The above results indicate that the molecular mobility of NaALG increases with the increasing amount of water molecules. With the increasing amount of non-freezing water in the $W_{\mathrm{c}}$ ranging from 0 to 0.5 , a decrease in $T_{\mathrm{g}}$ and an increase in the $\Delta C_{\mathrm{p}}$ were observed. The variation of $T_{\mathrm{g}}$ decrease agrees well with that of $\Delta C_{\mathrm{p}}$, suggesting that the system is a homogeneous mixture. It is reasonable to consider that hydrophilic sites of NaALG molecules are surrounded by non-freezing water until eight water molecules occupy the water-NaALG system. The maximum value of $W_{\text {nf }}$ shown in Figure 4 suggests that in addition to the above number of molecules, several more water molecules are restrained by NaALG, when the number of water molecules is insufficient to form ice. When a sufficient amount of free water filled the system, one or two water molecules which have been identified as non-freezing water from the DSC curve, detach themselves from the group of nonfreezing water molecules and become part of the group of freezing water molecules. The variation in $\Delta C_{\mathrm{p}}$ in Figure 5 also supports the above explanation. The liquid crystalline phase is also formed when eight to twelve water molecules surround the hydrophilic sites of NaALG.

Acknowledgments. The authors are grateful to Dr. H. Yoshida, Tokyo Metropolitan University for his helpful discussion.

\section{REFERENCES}

1. E. D. T. Atkins, I. A. Nieduszynski, W. Mackie, K. D. Parker, and E. E. Smolko, Biopolymers, 12, 1865 (1973).

2. E. D. T. Atkins, I. A. Nieduszynski, W. Mackie, K. D. Parker, and E. E. Smolko, Biopolymers, 12, 1879 (1973).

3. A. Haug, B. Larsen, and O. Smidsrod, Acta Chem. Scand., 21, 691 (1967).

4. D. A. Rees and E. J. Welsh, Angew. Chem. Int. Ed. Engl., 16, 214 (1977).

5. D. A. Rees, Adv. Carbohydr. Chem. Biochem., 24, 267 (1969).

6. K. Nakamura, T. Hatakeyama, and H. Hatakeyama, "Wood and Cellulosics," J. F. Kennedy, G. O. Phyllips, and P. A. Williams, Ed., Ellis Horwood Ltd., Chichester, 1987, p 23.

7. T. Hatakeyama, H. Yoshida, and H. Hatakeyama, Polymer, 28, 1282 (1987).

8. J. Mattai and J. T. Kwak, Macromolecules, 19, 1663 (1986).

9. P. Godard, J. J. Biebuyck, M. Daumerie, H. Naveau, and J. P. Mercier, J. Polym. Sci., 16, 1817 (1978). 
10. C. A. Angell, J. Shuppert, and J. C. Tucker, J. Phys. Chem., 77, 3092 (1973).

11. N.Ise and T. Okubo, Macromolecules, 11, 439 (1978).

12. N. Ise, T. Okubo, K. Yamamoto, H. Kawai, T. Hashimoto, M. Fugimura, and Y. Hiragi, J. Am. Chem. Soc., 102, 7901 (1980).

13. K. Nakamura, T. Hatakeyama, and H. Hatakeyama, Proceeding of the 24th Netsu Sokutei Toronkai, 1988, p 1223B.

14. T. Hatakeyama, H. Yoshida, K. Nakamura, and H. Hatakeyama, Food Hydrocolloids, 3, 301 (1989).

15. T. Hatakeyama, K. Nakamura, H. Yoshida, and H. Hatakeyama, Thermochemica Acta, 88, 223 (1985).

16. H. Hatakeyama, K. Nakamura, and T. Hatakeyama, in "Cellulose and Wood," C. Schuerch, Ed., Wiley Interscience, New York, N.Y., 1989, p 419.

17. H. Yoshida, K. Nakamura, T. Hatakeyama, and H. Hatakeyama, Polymer, 31, 693 (1990).

18. H. Hatakeyama, S. Hirose, and T. Hatakeyama, in "Lignin, Properties and Materials," ACS Symp. Ser. 397, W. G. Glasser and S. Sarkanen, Ed., American Chemical Society, Washington, D. C., 1989, p 205.

19. T. Hatakeyama, K. Nakamura, and H. Hatakeyama, Thermochemica Acta, 123, 153 (1988).

20. K. Nakamura, T. Hatakeyama, and H. Hatakeyama, Polymer, 24, 871 (1983).

21. H. Yoshida, T. Hatakeyama, K. Nakamura, and H. Hatakeyama, Kobunshi Ronbunshu, 46, 597 (1989).

22. H. Hatakeyama, Kagaku to Kogyo, 42, 878 (1989). 